\title{
Understanding Infliximab in Crohn's Disease: The Long-Term Outcomes
}

\author{
Dan Turner • Raffi Lev-Tzion
}

Published online: 23 December 2012

(C) Springer Science+Business Media New York 2012

Only a few years elapsed from the first clinical trial of infliximab in Crohn's disease (CD) in 1997 [1] to its widespread use in clinical practice [2]. This is a short interval given the novelty of the drug and its shockingly high cost. The rapid acceptance of the anti-TNF therapies despite the lack of long-term data could be easily understood in light of the striking unmet need for effective salvage therapies that was present prior to the anti-TNF era, when only one-third of patients had mild disease, judged longitudinally [3]. Indeed, anti-TNF medications brought rapid change to the management of IBD and improved the quality of life of countless patients. Accompanied by massive industry-driven aggressive marketing, more antiTNF drugs have been introduced including adalimumab, certolizumab pegol and golimumab, contributing further to the increasing use of biologics in IBD.

Although clinical trials are essential for evaluating the effectiveness of emerging therapies, standard trial design cannot be considered sufficient in view of its inherent limitations. Only approximately one-third of potentially eligible patients are enrolled into trials, imposing a significant selection bias which is further enhanced by the typical conduct of clinical trials in large referral centers. The meticulous follow-up during the trial, not routinely employed in clinical practice, imposes measurement bias; furthermore, the length of follow-up does not usually exceed 1-1.5 years. Given these limitations, the post-

D. Turner $(\bowtie) \cdot$ R. Lev-Tzion

Pediatric Gastroenterology and Nutrition Unit, Shaare Zedek

Medical Center, P.O. Box 3235, 91031 Jerusalem, Israel

e-mail: turnerd@szmc.org.il

D. Turner

The Hebrew University of Jerusalem, Jerusalem, Israel marketing, real-life evaluation of drugs, as performed by Seminerio et al. in this issue [4] is of utmost importance.

Seminerio et al. elegantly reported their long-term experience of patients treated with infliximab with a median follow-up of 6.4 years, the longest to date [4]. The medical records of 492 unselected patients (or 464 with outcome data, used here as the denominator to calculate rates) treated with infliximab at the Mayo Clinic (1998-2002) were systematically reviewed. The study showed an $86 \%$ initial response rate (or $80 \%$ calculated on an ITT basis), similar to the 82-89\% reported in most other publications such as the pediatric REACH trial [5], the Edmonton cohort [6], the large Leuven cohort [7], the Leeds cohort [8], and the Targan initial RCT [1] but higher than the short-term response rate achieved in the ACCENT trial $(65 \%)$ [2]. This figure (82-89\%) also includes those with partial response, variably defined in the different studies. In the current study, the complete response rate was $65 \%$, but it should be emphasized that the vast majority had only one or two induction doses rather than the current standard of a three-dose protocol.

The long-term outcome of the current study is shown in Fig. 1, benchmarked by some other long-term real-life reports, most notably the Leuven cohort, which reviewed the outcome of 614 patients [7] and the safety of 734 patients [9]. Direct comparison between the studies is challenging in view of the different follow-up periods and definitions of response as well as the variable inclusion of patients with episodic treatment and fistulizing disease. Nonetheless, some overall conclusions can be extrapolated along with estimation of long-term outcomes. The longterm failure rate (i.e., the need to discontinue infliximab for low effectiveness or unbearable adverse events) is high at $\sim 40 \%$. The comparable rates between the cohorts despite the differing follow-up periods (2-6.4 years) could be 
explained by heterogeneous inclusion criteria or by the observation that most failures are in the first year with a subsequent high likelihood for sustained benefit. The two outlying studies in Fig. 1a with lower failure rates excluded patients with episodic treatment, which probably also accounts for the lower reported rate of adverse events (Table 1). Considering the same reservations, the overall long term sustained success rate of infliximab is $\sim 50 \%$ (Fig. 1b). A total of $43 \%$ of those with outcome data in the current report of Seminerio et al. required at least one surgery at some time during the follow-up period after starting infliximab as compared with $24 \%$ in the Leuven cohort [7]. Most other reports did not report on surgery rate leaving open the question of whether infliximab alters the natural history of the disease.

Before we can address the question of whether biologics should be prescribed early in the disease course, we first need to know what happens to treated patients years after starting infliximab treatment. Indeed, even 6.4 years of follow-up may be too short for this lifelong disease, especially in pediatric-onset cases. In this report, only approximately $40 \%$ of patients treated with scheduled maintenance therapy still received the drug at the end of the 6.4-year follow-up period. The current study does not report the long-term outcome of the $14 \%$ who stopped infliximab for sustained remission. A recent study showed that among 115 patients who discontinued infliximab for sustained steroid-free remission, approximately $50 \%$ relapsed within 1 year, although reintroduction of infliximab was successful in $88 \%$ [10].

Seminerio et al. report 13 significant infections $(2.9 \%$ of the cohort) that could be attributed to the treatment, including two $(0.4 \%)$ that were lethal. Table 1 depicts the safety data, benchmarked by other selected real-life cohorts. The American TREAT registry for patients with IBD did not identify anti-TNF therapy as an independent risk factor for the development of serious infections [11] whereas the Leuven experience highlighted concomitant steroid therapy as a risk factor [9]. Although the present study reported an increased malignancy rate, the authors
Fig. 1 Discontinuation rates and long-term outcomes of infliximab in real-life cohorts (references are in Table 1). (1) Mayo Clinic 2012 includes the 464 patients with outcome data, (2) in The Netherlands cohort, those with $<3$ induction infusions and those with episodic protocol were excluded thus underestimating the primary and secondary nonresponse rate, (3) infliximab in those labeled as secondary loss of response was discontinued only after dose intensification in all cohorts, (4) "\% episodic" refers to the percentage of patients in the cohort who were at least initially prescribed episodic infliximab treatment, (5) in Fig. 1b, the Mayo Clinic cohort had a high drop-out rate of $25 \%$ (lost to follow-up or other technical reasons) probably accounting for the outlying lower successful rate. $F U$ follow-up
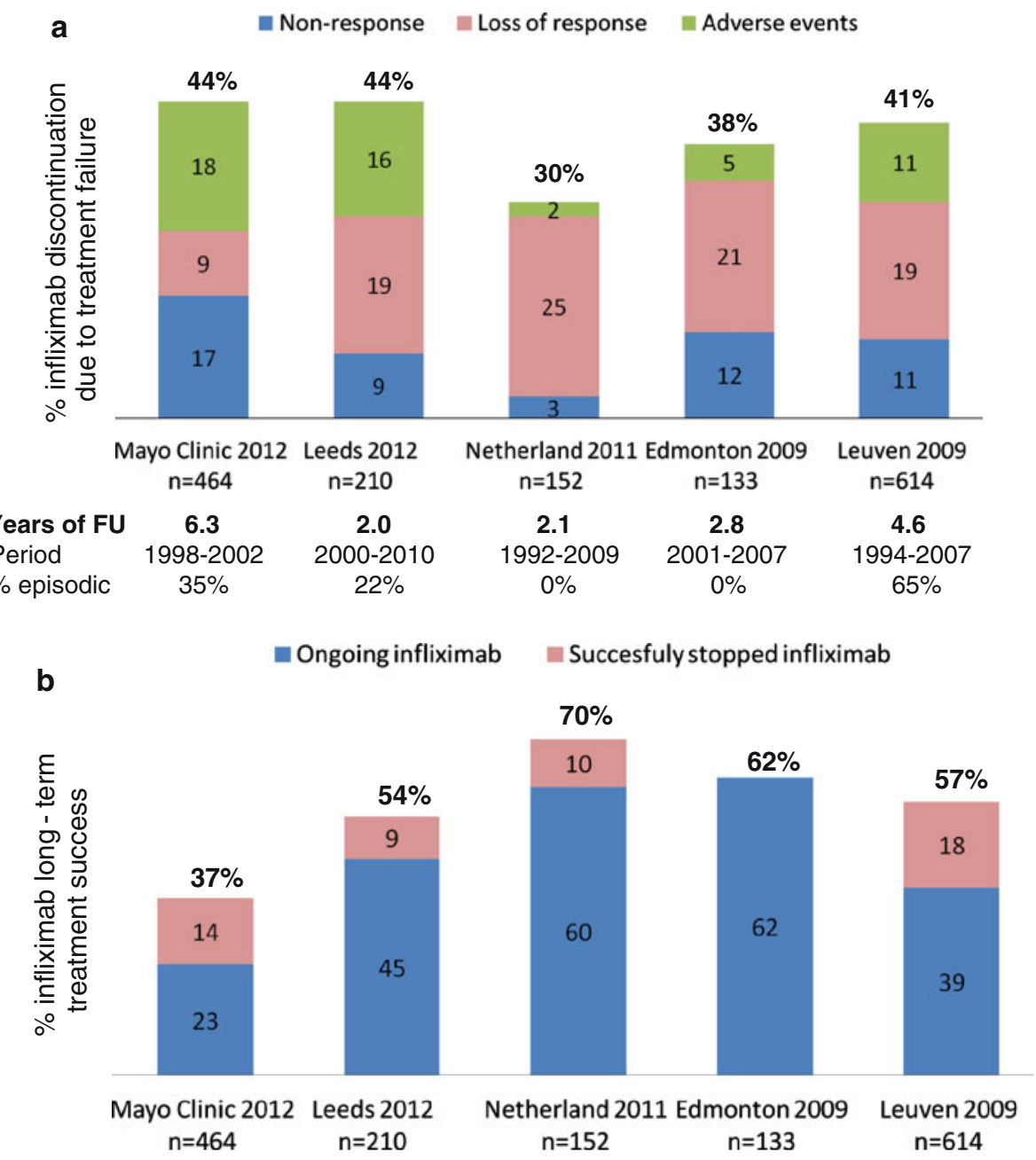
Table 1 Cohort studies with at least 2 years of follow-up from which enough data could be retrieved (details of the studies are shown in Fig. 1)

\begin{tabular}{|c|c|c|c|}
\hline Study & Severe adverse events & Cancer & Deaths \\
\hline $\begin{array}{l}\text { Mayo Clinic } \\
\text { (DDS } 2012 \\
\text { current } \\
\text { publication) }\end{array}$ & $\begin{array}{l}\text { Severe infections in } 17 \% \text { of those with } \\
\text { outcome data (but only } 2 \% \text { stopped } \\
\text { infliximab as a consequence) }\end{array}$ & $\begin{array}{l}\text { Malignancy in } 31(6.7 \% \text {, solid, skin } \\
\text { and hematologic). SMR of } 2.2 \\
(95 \% \text { CI 1.4-3.2) }\end{array}$ & $\begin{array}{l}\text { Of } 28 \text { deaths, } 9 \text { occurred within } \\
12 \text { weeks of an infusion }(1.9 \%), 2 \text { of } \\
\text { which were due to infections }\end{array}$ \\
\hline $\begin{array}{l}\text { Leuven } 2009 \\
{[7,9]}\end{array}$ & $\begin{array}{l}13 \text { versus } 19 \% \text { in } 734 \text { controls } \\
(p=0.45) \\
\text { Serious infections in } 6 \text { versus } 9 \% \text { in } \\
\text { controls }\end{array}$ & $\begin{array}{l}\text { Malignancy in } 21(2.9 \%)(0.4 / 100 \\
\text { patient years) versus } 0.5 / 100 \text { patient- } \\
\text { years in the control group }\end{array}$ & $\begin{array}{l}1 \text { related and } 3 \text { possibly related deaths } \\
\text { (0.7\% of responders) }\end{array}$ \\
\hline Leeds 2012 [8] & $7 \%$ of infections attributed to infliximab & Malignancy in $2(1 \%)$ & 1 possibly related death $(0.5 \%)$ \\
\hline $\begin{array}{l}\text { Dutch pediatric } \\
\text { cohort } 2011 \\
{[13]}\end{array}$ & $\begin{array}{l}\text { Serious infections in } 2(3 \%) \text { of whom } 1 \\
\text { died }\end{array}$ & $0(0 \%)$ & 1 related death $(0.7 \%)$ \\
\hline $\begin{array}{l}\text { Edmonton cohort } \\
2009 \text { [6] }\end{array}$ & Serious infections in $1(0.8 \%)$ & $0(0 \%)$ & $0(0 \%)$ \\
\hline
\end{tabular}

SMR standardized morbidity ratio (compared with the national SEER data)

rightly state that the increase could be also attributed to the underlying disease, other concomitant medications, and referral bias.

Several inherent shortcomings of this study should be highlighted, since they can underestimate drug efficacy. As many as $80 \%$ of patients did not receive a three-dose induction protocol with $35 \%$ initiated on an episodic protocol; both are no longer practiced. Indeed, in the Leuven cohort, those started on episodic treatment had a significantly higher rate of hospitalization than those starting with scheduled maintenance infusions (47 vs. $26 \%, p<0.001$ ) [7]. Moreover, there are strong referral and selection biases favoring drug failure. Besides the fact that the Mayo Clinic is a large referral center attracting more severe patients, it is plausible to assume that when infliximab was just introduced, it was prescribed mainly to the more severe and resistant cases with longer disease duration than is practiced now. Indeed, $55 \%$ of patients in the current cohort underwent at least one surgery prior to trying infliximab.

On the one hand, we need long-term outcome data of drugs, but on the other hand management schemes practiced in the long-term rapidly become outdated in light of the astonishingly rapid progress of drug development. The future of infliximab treatment involves dose optimization based on individual drug levels [12]. The current report and others provide the basic average outcome data upon which we now need to improve by implementing innovative predictive schemes, based on clinical, genomic, and biochemical factors. Since most biases in this report are counter to drug efficacy, the reported outcomes should be viewed as conservative, minimum rates. The safety outcomes are more difficult to extrapolate as they may be actually worse with scheduled maintenance therapy and the more aggressive selective "top-down" approach now often recommended.

In summary, doubt remains regarding the long-term outcome and safety of infliximab in the treatment of Crohn's disease although every succeeding report like that of Seminerio et al. provides a closer approximation to the true rates. From this study and others, the cumulative probability of discontinuing infliximab at or before 5 and 10 years is approximately $\sim 40-50$ and $\sim 60-70 \%$, respectively, mostly due to lack of sustained clinical benefit or adverse events. These probabilities should be factored into the increasing debate regarding the desirability of "step-up" versus "top-down" approaches.

\section{References}

1. Targan SR, Hanauer SB, van Deventer SJ, et al. A short-term study of chimeric monoclonal antibody cA2 to tumor necrosis factor alpha for Crohn's disease. Crohn's disease cA2 Study Group. N Engl J Med. 1997;337:1029-1035.

2. Hanauer SB, Feagan BG, Lichtenstein GR, et al. Maintenance infliximab for Crohn's disease: the ACCENT I randomised trial. Lancet. 2002;359:1541-1549.

3. Griffiths AM, Nguyen P, Smith C, MacMillan JH, Sherman PM. Growth and clinical course of children with Crohn's disease. Gut. 1993;34:939-943.

4. Seminerio JL, Loftus EV Jr, Colombel J-F, Thapa P, Sandborn WJ. Infliximab for Crohn's disease: the first 500 patients followed up through 2009. Dig Dis Sci. doi:10.1007/s10620-0122405-z.

5. Hyams J, Crandall W, Kugathasan S, et al. Induction and maintenance infliximab therapy for the treatment of moderate-tosevere Crohn's disease in children. Gastroenterology. 2007;132: 863-873; quiz 1165-1166.

6. Teshima CW, Thompson A, Dhanoa L, Dieleman LA, Fedorak RN. Long-term response rates to infliximab therapy for Crohn's disease in an outpatient cohort. Can J Gastroenterol. 2009;23: 348-352. 
7. Schnitzler F, Fidder H, Ferrante M, et al. Long-term outcome of treatment with infliximab in 614 patients with Crohn's disease: results from a single-centre cohort. Gut. 2009;58:492-500.

8. Sprakes MB, Ford AC, Warren L, Greer D, Hamlin J. Efficacy, tolerability, and predictors of response to infliximab therapy for Crohn's disease: a large single-centre experience. J Crohns Colitis. 2012;6:143-153.

9. Fidder H, Schnitzler F, Ferrante M, et al. Long-term safety of infliximab for the treatment of inflammatory bowel disease: a single-centre cohort study. Gut. 2009;58:501-508.

10. Louis E, Mary JY, Vernier-Massouille G, et al. Maintenance of remission among patients with Crohn's disease on antimetabolite therapy after infliximab therapy is stopped. Gastroenterology. 2012;142:63-70.e65; quiz e31.

11. Lichtenstein GR, Feagan BG, Cohen RD, et al. Serious infections and mortality in association with therapies for Crohn's disease: TREAT registry. Clin Gastroenterol Hepatol. 2006;4:621-630.

12. Seow $\mathrm{CH}$, Newman A, Irwin SP, Steinhart AH, Silverberg MS, Greenberg GR. Trough serum infliximab: a predictive factor of clinical outcome for infliximab treatment in acute ulcerative colitis. Gut. 2010;59:49-54.

13. de Bie CI, Hummel TZ, Kindermann A, et al. The duration of effect of infliximab maintenance treatment in paediatric Crohn's disease is limited. Aliment Pharmacol Ther. 2011;33:243-250. 